\title{
Prolactin I microsatellite as genetic markers for characterization of five Oreochromis tilapia species and two Oreochromis niloticus strains
}

\section{Jing-Ruei Chi ${ }^{1,2,3}$, Chang-Wen Huang ${ }^{4}$, Shao-Yang $\mathrm{Hu}^{5 *}$ and Jen-Leih $\mathrm{Wu}^{2 *}$}

${ }^{1}$ Department of Biochemical Science and Technology, National Taiwan University, Taipei, Taiwan

${ }^{2}$ Institute of Cellular and Organismic Biology, Academia Sinica, Taipei, Taiwan

${ }^{3}$ Food Industry Research and Development Institute, Hsinchu 30062, Taiwan

${ }^{4}$ Department of Aquaculture, National Taiwan Ocean University, Keelung 202, Taiwan

${ }^{5}$ Department of Biological Science and Technology, National Pingtung University of Science and Technology, Pingtung, Taiwan

\begin{abstract}
Hybrid tilapia is a major aquaculture food fish species in developing countries. The development of molecular markers to characterize and trace tilapia species is necessary to improve tilapia quality and enhance the competitive advantage of the aquaculture industry. Microsatellite markers have been suggested to assist breeding, species identification, and traceability system for tilapia. We used six microsatellites markers located within growth-related genes to discriminate between several tilapia species. We found that a combination of two microsatellites markers located within the proximal promoter of the prolactin I (PRL I) gene, PRL I-MS01 and PRL I-MS02, were able to discriminate between five Oreochromis tilapia species (O. mossambicus, O. aureus, O. niloticus, $O$. hornorum and $O$. spilurus) and two O. niloticus strains that exhibit the distinctive growth traits. Furthermore, we found that PRL I-MS01 microsatellite marker was able to trace parental origin of hybrid tilapia. Thus, this marker is a potentially beneficial tool for a tilapia traceability system. We conclude that the GT tandem repeats in PRL I-MS01 and CA tandem repeats in PRL I-MS02 are useful genetic markers to characterize diverse tilapia species, assist in the genetic tracing and conventional breeding of superior strains and strengthen the management of the tilapia aquaculture industry. There was strong relationship between the cold and both temperature at death and cumulative degree hours represented by negative correlation coefficient for all tested fish. There was no correlation between cold tolerance and fish size for all tested fish. The cooling degree hours were significantly different between the selected and non-selected $O$. niloticus $(P<0.005)$. The selected $O$. aureus exhibited greater cold tolerance than the non-selected and death began at $14.1^{\circ} \mathrm{C}$, while non-selected occurred at $15.2^{\circ} \mathrm{C}$.
\end{abstract}

Keywords: Prolactin; Tilapia; Microsatellite; Growth; Traceability

\section{Introduction}

Tilapia is an important aquacultural fish species globally because of its large size, high reproductive rate, rapid growth and palatability. According to the Food and Agriculture Organization (FAO), global tilapia production exceeded more than 4.2 million metric tons with a sales value of more than $\$ 5$ billion in 2012. Because tilapia products are known for highly palatable taste and hygienic quality, therefore they have become popular worldwide. As a result, tilapia has become the one of the most important exported fish species and is a major source of income in developing countries. In general, high-quality tilapia products are derived from hybrids of superior tilapia strains that have been developed using advanced aquacultural technology. Most of these superior tilapia strains are bred using traditional generational selection. The characterization and maintenance of these superior tilapia strains are important to enhance the competitive advantage in aquaculture industry. Furthermore, food contamination occurs frequently in fish and fishery products. Consumers are increasingly concerned about what they eat and whether their foods are from high-quality and safe sources. A traceability system for the fishery chain is the most important tool to manage food safety [1]. Such a system can trace fish and fishery products to their farm of origin if toxins, diseases or unsatisfactory qualities are detected in the market. Most traceability schemes involve documentation at every processing step. However, it is difficult to verify theses records in the event of fraudulent activities. The development of molecular marker technology is needed to facilitate conventional selective breeding, sustain the tilapia aquaculture industry, promote tilapia quality and confirm traceability documentation [2].

Several molecular markers have been used to characterize tilapia species and permit tilapia traceability, including restriction fragment length polymorphisms (RFLPs), random amplified polymorphic DNA
(RAPD), amplified fragment length polymorphisms (AFLPs) and microsatellites [3-8]. Among these molecular markers, microsatellites have been commonly used because they are highly reproducible, polymorphic, co-dominant and widely distributed throughout the genome [9]. Microsatellites are repeated sequences of DNA throughout the genome. Most of microsatellite loci are associated with anonymous genomic segments [9]. However, an increasing body of research has demonstrated that some microsatellites are located with promoter and transcribed regions of genome and may be involved in regulating gene expression and function [10-13]. These functional microsatellites may cause distinct phenotypes or influence physiological functioning by directly or indirectly affecting the expression and function of a given gene $[11,14]$. Therefore, functional microsatellites can be used as genetic markers to characterize the phenotypes that result from the expressional variation of a given gene.

*Corresponding authors: Shao-Yang Hu, Ph.D., Department of Biological Science and Technology, National Pingtung University of Science and Technology, No. 1, Hseufu Road, Pingtung, Taiwan, Tel.: +886-8-7703202 ext. 6356; Fax: +8868-7740584; E-mail address: syhu@mail.npust.edu.tw

Jen-Leih Wu, Ph.D., Laboratory of Marine Molecular Biology and Biotechnology 301 , Institute of Cellular and Organismic Biology, Academia Sinica, No. 128, Section 2 Academia Road, Nankang, Taipei 115, Taiwan, Tel.: +886-02-27899568; Fax: +886-227824595; E-mail: jwu@gate.sinica.edu.tw

Received May 20, 2014; Accepted July 24, 2014; Published August 03, 2014

Citation: Chi JR, Huang CW, Hu SY, Wu JL (2014) Prolactin I microsatellite as genetic markers for characterization of five Oreochromis tilapia species and two Oreochromis niloticus strains. J Aquac Res Development 5: 251 doi:10.4172/21559546.1000251

Copyright: (c) 2014 Chi JR, et al. This is an open-access article distributed under the terms of the Creative Commons Attribution License, which permits unrestricted use, distribution, and reproduction in any medium, provided the original author and source are credited. 
Nile tilapia can live longer than 10 years. Food availability and water temperature appear to be the limiting factors to growth for O. niloticus. Optimal growth is achieved at $28-36^{\circ} \mathrm{C}$ and declines with decreasing temperature. The ability to vary their diet may also result in variation in growth. In aquaculture ponds, $O$. niloticus can reach sexual maturity at the age of 5-6 months. Growth enhancement is a desired phenotype for tilapia in the aquaculture industry. Several growth-related genes are involved in cell proliferation and somatic growth, including growth hormone $(\mathrm{GH})$, insulin-like growth factors-2 (IGF-2), prolactin-I (PRL-I) and insulin gene [15-18]. In the present study, we elucidate the ability of six microsatellite markers within these growth-related genes to characterize several tilapia species. We found that five Oreochromis species and two strains of $O$. niloticus can be differentiated by the microsatellite markers PRL I-MS01 and PRL I-MS02. The parentage of hybrid tilapia can also be traced by PRL I-MS01. We conclude that PRL I microsatellite markers are useful genetic markers for traceability systems and for breeding superior strains in the tilapia aquaculture industry.

\section{Materials and Methods}

\section{Tilapia species and cultivation}

Five Oreochromis tilapia species, [O. mossambicus (M), O. aureus (A), O. hornorum (H), O. spilurus (S), O. niloticus (N)] and one O. niloticus $\left(\mathrm{N}_{\mathrm{F}}\right)$ strain with a rapid-growth phenotype were obtained from the Freshwater Aquaculture Research Center (FARC) of the Aquaculture Research Institute, Council of Agriculture (Lukang, Changhua, Taiwan). Fish were maintained in one-ton tanks equipped with circulating water at $25^{\circ} \mathrm{C}$.

\section{Genotypic analysis of tilapia using growth-related microsatellite markers}

Genomic DNA of diverse Oreochromis tilapia species was extracted from $20 \mathrm{mg}$ of muscle tissue using the Master Pure ${ }^{\mathrm{TM}}$ Complete DNA Purification Kit (Epicentre Biotechnologies, Wisconsin, WI, USA) according to the manufacturer's protocol. Each genomic DNA sample was quantified using a Nano Drop ND-1000 spectrophotometer (Nano Drop Technologies, Inc., Wilmington, DE, USA). Genomic DNA samples were adjusted to a final concentration of $100 \mathrm{ng} / \mathrm{L}$. Primer sequences for growth-related microsatellite loci were designed according to the methods of Yue and Orban [19] and are listed in Table 1. PCR was performed in $50-\mu$ volumes containing $1 \times$ PCR buffer, 2 $\mathrm{mM} \mathrm{MgSO}_{4}, 0.2 \mathrm{mM}$ dNTP, $200 \mathrm{nM}$ of primers, 1.0 unit of Platinum Taq high-fidelity DNA polymerase and $100 \mathrm{ng}$ of genomic DNA. PCR was carried out as follows: $94^{\circ} \mathrm{C}$ for $2 \mathrm{~min} ; 35$ cycles at $94^{\circ} \mathrm{C}$ for $30 \mathrm{~s}$, $55^{\circ} \mathrm{C}$ for $30 \mathrm{~s}$, and $68^{\circ} \mathrm{C}$ for $30 \mathrm{~s}$; and a final cycle at $72^{\circ} \mathrm{C}$ for $10 \mathrm{~min}$. A
1- $\mu \mathrm{l}$ aliquot of each PCR product was used for genotypic analysis in a 2100 Bioanalyzer equipped with Expert version B.01.02.S1136 software and a DNA 1000 Lab Chip kit (Agilent Technologies, Palo Alto, CA, USA). The lengths of PCR products were calculated by the software based on the product retention times compared to size standards. A total of 25 samples $(n=25)$ of each tilapia species were genotyped.

Bardakci [5] reported that feed treated with 17 alpha methyl testosterone (MT) is used to manipulate the gender of early tilapia fry. A series of experiments demonstrated that the analytical procedure for detecting MT in feeds lacked high precision and on average biased results. Low MT was uniformly mixed with feed by spraying an MTalcohol solution on feed while it was blended in an industrial ribbon mixer. Alcohol volumes ranging from 15 to $150 \mathrm{ml} / \mathrm{kg}$ were equally effective at dispersing MT in feed. The concentrations of MT in feeds consistently declined over time if the storage temperature was $25^{\circ} \mathrm{C}$ or higher. Freezing preserved the MT in feed, and the refrigeration of feed fabricated to contain $60 \mathrm{mg}$ MT/ $\mathrm{kg}$ maintained acceptable MT concentrations during 6 months of storage.

\section{Growth performance experiment}

Five experimental groups [progeny of $q$ O. aureus (A) mated to

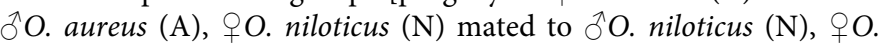
niloticus $\left(\mathrm{N}_{\mathrm{F}}\right)$ mated to $\supset$ O. niloticus $\left(\mathrm{N}_{\mathrm{F}}\right)$, ○O. niloticus $(\mathrm{N})$ mated to $\widehat{\partial} O$. aureus $(\mathrm{A})$ and $q$ O. niloticus $\left(\mathrm{N}_{\mathrm{F}}\right)$ mated to $\widehat{\sigma} O$. aureus $(\mathrm{A})$ were used to evaluate growth performance. Larvae from each group were grown for one month in temperature-controlled 20-L plastic aquaria. Subsequently, 120 juvenile fish from each group were shifted to a pond ( $5 \mathrm{~m} \mathrm{x} 3 \mathrm{~m} \mathrm{x} 1 \mathrm{~m}$ ) with a circulating water system and fed a commercial fodder (23\% protein content) at a rate of approximately $1.5-5 \%$ of fish body weight twice daily for 20 weeks ( $n=120$; duplicate). Thirty fish from each experimental group were randomly sampled on one monthly basis to determine body length, total body length and body weight. Body length and total body length were measured as the distance from the tip of the mouth to the hypural bone and from the tip of the month to the caudal fin, respectively [20]. Specific growth rate (SGR) was calculated using the following equation: SGR $(\% /$ day $)=[(\ln$ $\left.\left.\mathrm{W}_{2}-\ln \mathrm{W}_{1}\right) / \mathrm{t}_{2}-\mathrm{t}_{1}\right] \times 100$, where $\mathrm{t}_{1}$ is the time at the beginning of growth, $t_{2}$ is the time at the end of growth, $W_{1}$ is the average body weight or body length at $t_{1}$, and $\mathrm{W}_{2}$ is the average body weight or body length at $t_{2}$.

\section{Parentage assignment}

Hybrid tilapia population obtained by mating O. niloticus strains $\left(\mathrm{N}\right.$ or $\left.\mathrm{N}_{\mathrm{F}}\right)$ to O.aureus $(\mathrm{A})\left(\mathrm{NxA}\right.$ or $\left.\mathrm{N}_{\mathrm{F}} \mathrm{xA}\right)$ were used to study parentage assignment with PRL I microsatellite markers. Genomic DNA aliquots (100 ng) from hybrid tilapia and their parental strains were used as

\begin{tabular}{|c|c|c|c|c|}
\hline Primer name & Primer sequence (5'-3') & Position within gene & Repeat motif & References (Gene Bank Accession no.) \\
\hline \multirow{2}{*}{ PRL I-MS01 } & F:GTTAGCCCCCTCCTCACTCT & \multirow{2}{*}{ promoter of prolactin } & \multirow{2}{*}{ GT } & \multirow{2}{*}{ X92380 } \\
\hline & R:ACCTTGCTCGTCACACCTG & & & \\
\hline \multirow{2}{*}{ PRL I-MS02 } & F:TCGTGTCTTGTGGGGAAACC & \multirow{2}{*}{ promoter of prolactin } & \multirow{2}{*}{$\mathrm{CA}$} & \multirow{2}{*}{ X92380 } \\
\hline & R:TGAATGGATGCAACAGGATG & & & \\
\hline \multirow{2}{*}{ IGF-II-MS01 } & F:TCCCCAGCTGGAAGATGTGTCACG & \multirow{2}{*}{ promoter of IGF-II } & \multirow{2}{*}{ CT } & \multirow{2}{*}{ AF033802 } \\
\hline & R:CTGGACGCAGCTGAAATCCTGTGG & & & \\
\hline \multirow{2}{*}{ IGF-II-MS03 } & F:ATGCTAGCAAACATCAAAGGTC & \multirow{2}{*}{ 3'UTR of IGF-II } & \multirow{2}{*}{ АTCT } & \multirow{2}{*}{ AF033804 } \\
\hline & R:GATATGCTGATGATGCACAGAGTC & & & \\
\hline \multirow{2}{*}{ GH-MS01 } & F:CCAGCCATGAACTCAGGTAAGACA & \multirow{2}{*}{ intron 1 of $\mathrm{GH}$} & \multirow{2}{*}{ TGTC } & \multirow{2}{*}{ M97765 } \\
\hline & R:TGCTGAGAGGAGACGCCCAAACA & & & \\
\hline \multirow{2}{*}{ ISP-MS01 } & F:GAGCTGAGCAGATGGAGCAGAAG & \multirow{2}{*}{ 5'UTR of insulin precursor } & \multirow{2}{*}{$\mathrm{CA}$} & \multirow{2}{*}{ AF038123 } \\
\hline & F:GAGCTGAGCAGATGGAGCAGAAG & & & \\
\hline
\end{tabular}

Table 1: Primer sequences used in this study and repeat motifs of six microsatellites located within growth-related genes. 
PCR templates. A 1- $\mu$ l aliquot of each PCR product was subjected to genotypic analysis using a 2100 Bioanalyzer equipped with Expert version B.01.02.S1136 software and DNA 1000 LabChip kits (Agilent Technologies).

\section{Identification of tandem repeats in PRL I microsatellite loci}

Genomic DNA was extracted from the progeny of $\mathrm{NxN}$ and $\mathrm{N}_{\mathrm{F}} \mathrm{xN}_{\mathrm{F}}$ tilapia as described above (Genotypic analysis of tilapia using growthrelated microsatellite markers). Genomic DNA from both populations was used in PCR reactions with PRL I-MS01 and PRL I-MS02 primers. The major PCR product bands were separated by electrophoresis on a $3 \%$ agarose gel and then purified using a QIAquick gel extraction kit (Qiagen, Düsseldorf, Germany). PCR products containing tandem repeats were ligated into the pGEMT-T Easy vector (Promega, Madision, WI, USA) for sequencing.

\section{Results}

\section{PRL I microsatellites can be used to discriminate between} tilapia species

Tilapia species differ in growth performance due to their distinct genetic backgrounds. We elucidate the ability of six growth-related microsatellites regions found in the growth-related gene IGF-II, PRL I, GH and insulin to discriminate between five Oreochromis tilapia species. Of these microsatellites loci, only two PRL I microsatellites were able to distinguish between different tilapia species. All tilapia species examined except $O$. spirulus could be identified using PRL I-MS01 microsatellite marker. Two major alleles of the PRL I-MS01 microsatellite locus (312 bp and $346 \mathrm{bp}$ ) were observed in O. aureus. Two alleles (290 bp and $320 \mathrm{bp}$ ) were observed in O. mossambicus. Two major alleles (302 bp and $338 \mathrm{bp}$ ) were observed in O. hornorum, and two alleles ( $260 \mathrm{bp}$ and $288 \mathrm{bp}$ ) were observed in O. niloticus. Although two major alleles (286 bp and $318 \mathrm{bp}$ ) were found in O. spirulus; the allele sizes were too similar to distinguish in O. mossambicus (Figure 1A). In contrast to PRL I-MS01, the PRL I -MS02 microsatellite marker

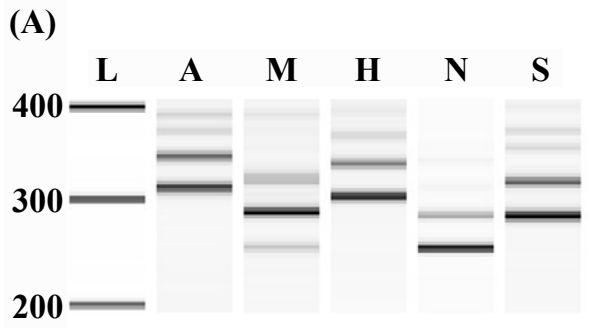

(B)

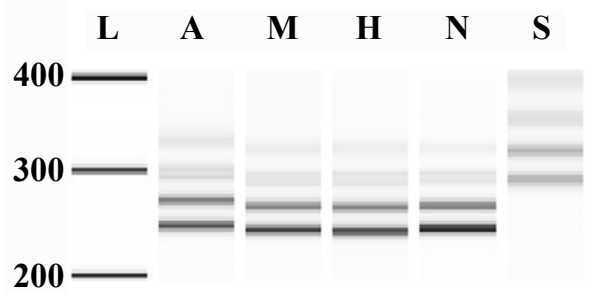

Figure 1: Characterization of Oreochromis tilapia species by PRL I microsatellite markers. PRL I-MS01 (A) and PRL I-MS02 (B) genotypes were determined using an Agilent 2100 Bioanalyzer. L: molecular weight ladder; $\mathrm{A}: \mathrm{O}$. aureus; $\mathrm{M}: \mathrm{O}$. mossambicus; $\mathrm{H}$ : O. hornorum; $\mathrm{N}$ : O. niloticus; S: O. spilurus.
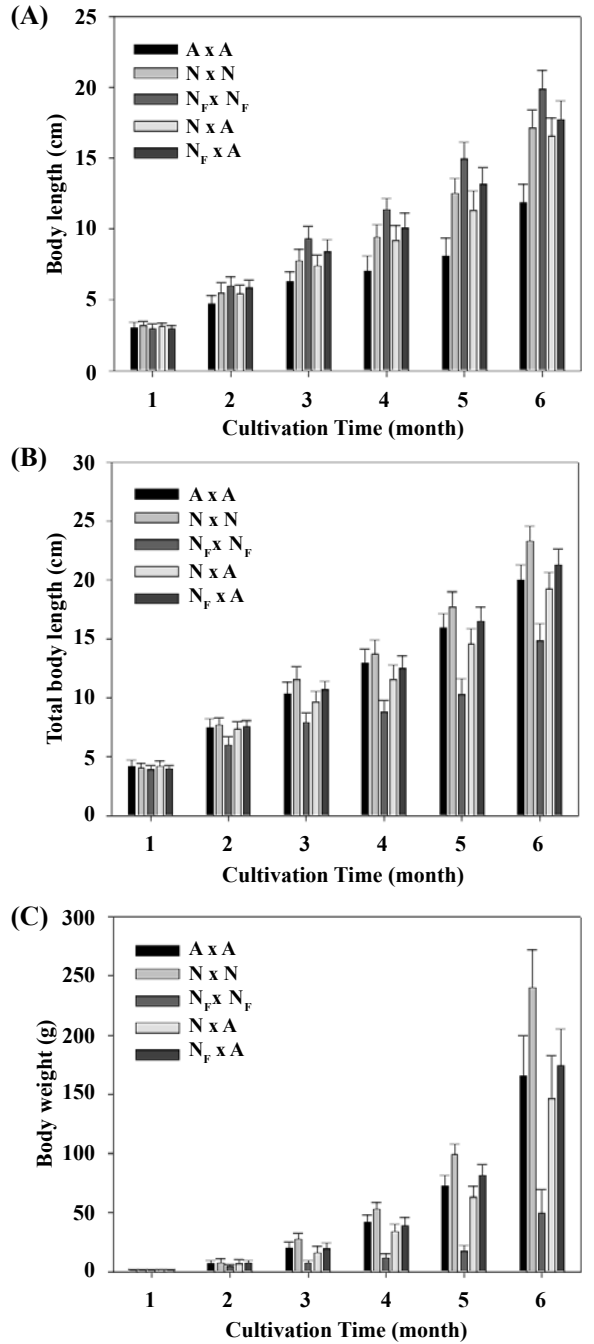

Figure 2: Comparison of growth performance between $O$. aureus (A), $O$ niloticus $(\mathrm{N})$, O niloticus $\left(\mathrm{N}_{\mathrm{F}}\right)$ and hybrid tilapia. The phenotypic traits (mean $\pm S D$ ) of body length $(A)$, total body length $(B)$ and body weight (C) were evaluated at one-month intervals for six months $(n=60)$. AxA: progeny of $O O$. aureus $(A)$ mated to $O$. aureus $(A)$. NxN: progeny of

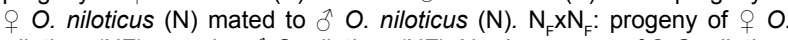
niloticus (NF) mated to $\widehat{O} O$. niloticus $(\mathrm{NF}) . \mathrm{N} \times \mathrm{A}$ : progeny of $q \mathrm{O}$. niloticus $(\mathrm{N})$ mated to $\delta \mathrm{O}$. aureus $(\mathrm{A}) . \mathrm{N}_{\mathrm{F}} \times \mathrm{A}$ : progeny of $q$ O. niloticus $\left(\mathrm{N}_{\mathrm{F}}\right)$ mated to $\hat{O} \mathrm{O}$. aureus $(\mathrm{A})$.

could differentiate only O. spilurus from the other tilapia species. Two major bands ( $288 \mathrm{bp}$ and $316 \mathrm{bp}$ ) were detected in O. spilurus. However, the other four species exhibited similar allele patterns that could not be distinguished (Figure 1B). A few additional genotypes were observed in each species, but they did not affect our ability to distinguish each species. These results suggest that the combination of PRL I-MS01 and PRL I-MS02 can efficiently discriminate between the five tilapia species studies.

The acclimatizing the fry was done at $20^{\circ} \mathrm{C}$ for 48 hours. After that aquarium water temperature was monitored each hour from the beginning to the end of the experiment. The temperature measurements were done hourly, while the dissolved oxygen (DO), $\mathrm{pH}$, total ammonia, nitrate and nitrite were measured once a day, using a WTWR multi $340 \mathrm{i}$ meter and HACH kits. Dissolved oxygen ranged between 6.1 and $10.3 \mathrm{mg} / \mathrm{l} ; \mathrm{pH}, 7.9-8.3$; ammonia, 0.01-0.1 mg/l; nitrate, $0.5-2 \mathrm{mg} / \mathrm{l}$; and 
Citation: Chi JR, Huang CW, Hu SY, Wu JL (2014) Prolactin I microsatellite as genetic markers for characterization of five Oreochromis tilapia species and two Oreochromis niloticus strains. J Aquac Res Development 5: 251 doi:10.4172/2155-9546.1000251

Page 4 of 7

nitrite, $0.01-0.02 \mathrm{mg} / \mathrm{l}$. Aquaria were cleaned twice daily by suction to remove faeces. Water that was removed during aquarium cleaning was replaced with clean water pre-cooled to the same temperature with ice cubes.

\section{Growth performance of $O$. niloticus strains}

The $\mathrm{N}_{\mathrm{F}}$ strain, which exhibited rapid growth compare to the original $\mathrm{N}$ strain, was developed through generational selective breeding. To demonstrate that the $\mathrm{N}_{\mathrm{F}}$ strain possessed the rapid-growth phenotype, we measured the growth curve of $\mathrm{N}_{\mathrm{F}}$ and $\mathrm{N}$ strain over one month. Most commercial tilapia is derived from hybrids of O. niloticus and $O$. aureus. Therefore, we also evaluated the growth performance of the hybrid progeny of $\mathrm{N}_{\mathrm{F}} \mathrm{xA}$ and $\mathrm{NxA}$. The $\mathrm{N}_{\mathrm{F}} \mathrm{xN}_{\mathrm{F}}$ progeny population exhibited better growth performance in body length and body weight than $\mathrm{NxN}$ population. Among hybrid populations, the $\mathrm{N}_{\mathrm{F}} \mathrm{xA}$ population showed better growth performance in body length and body weight than the NxA population. Growth performance traits increased in the following order: $\mathrm{N}_{\mathrm{F}} \mathrm{x} \mathrm{N}_{\mathrm{F}}>\mathrm{N}_{\mathrm{F}} \mathrm{xA}>\mathrm{NxN}>\mathrm{NxA}>\mathrm{AxA}$ (Figure 2). The order of SGR value based on body length or weight for each population was consistent with the growth performance. As shown in Table $2, \mathrm{~N}_{\mathrm{F}} \times \mathrm{N}_{\mathrm{F}}$ progeny exhibited the highest SGR value. Weight-based SGR values in decreasing order were as follows: $3.47 \%$ g/day for $\mathrm{N}_{\mathrm{F}} \times \mathrm{N}_{\mathrm{F}} ; 3.18 \%$ g/day for $\mathrm{N}_{\mathrm{F}} \times \mathrm{A} ; 3.16 \% \mathrm{~g} /$ day for $\mathrm{N} \times \mathrm{N} ; 2.94 \% \mathrm{~g} /$ day for $\mathrm{N} \times \mathrm{A}$ group;

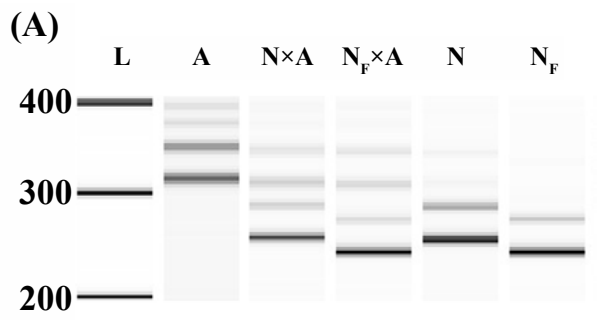

(B)

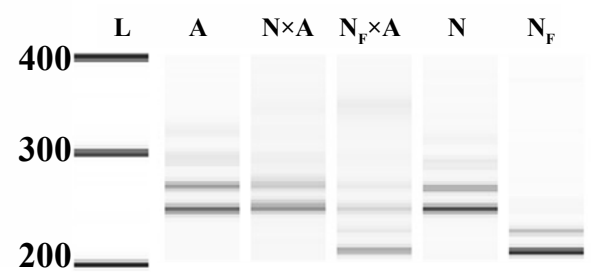

Figure 3: Traceability of hybrid tilapia using PRL I microsatellite markers PRL I-MS01 (A) and PRL I-MS02 (B) genotypes were determined using an Agilent 2100 Bioanalyzer. NxA: progeny of $O$ O. niloticus $(\mathrm{N})$ mated to $O$. aureus $(A) . N_{F} \times A$ : progeny of $O O$. niloticus $\left(N_{F}\right)$ mated to $O$. aureus(A).A: paternal $O$. aureus $(\mathrm{A})$; $\mathrm{N}$ : maternal $O$. niloticus $(\mathrm{N}) ; \mathrm{N}_{\mathrm{F}}$ : maternal O. niloticus $\left(\mathrm{N}_{\mathrm{F}}\right)$. and $2.44 \% \mathrm{~g} /$ day for $\mathrm{A} \times \mathrm{A}$. SGR values based on body length were also calculated. The $\mathrm{N}_{\mathrm{F}} \times \mathrm{N}_{\mathrm{F}}$ also exhibited the highest length-based SGR value. These results suggest that the rapid growth performance of $\mathrm{N}_{\mathrm{F}}$ compared $\mathrm{N}$ is due to differences in genetic background.

\section{PRL I microsatellite markers are useful to distinguish between O. niloticus strains}

To distinguish between the two strains of O. niloticus $\left(\mathrm{N}_{\mathrm{F}}\right.$ and $\mathrm{N}$ ), we analyzed the same six microsatellite loci within the growth related-genes IGF-II, PRL I, GH and insulin. The polymorphism and genotypic proportions in the $\mathrm{N}$ and $\mathrm{N}_{\mathrm{F}}$ strains are shown in Table 3 . IGF-II-MS03 was highly variable. A total of 19 genotypes were found in the two strains. We found eleven genotypes for PRL I-MS02, nine genotypes for GH-MS01, seven genotypes for PRL I-MS01, seven genotypes for ISP-MS01 and a six-allele locus for IGF II-MS01. Each genotype consists of two alleles at each locus, one smaller and one larger. Among these microsatellite markers, only PRL I-MS01 and PRL I-MS02 were able to discriminate between the $\mathrm{N}$ and $\mathrm{N}_{\mathrm{F}}$ strains of $O$. niloticus. PRL I-MS01 genotypes included 258/284 bp, 260/286 bp, 260/288 bp, 264/288 bp and 264/290 bp in the N strain and 248/274 bp and 250/276 bp in the $\mathrm{N}_{\mathrm{F}}$ strain. For PRL I-MS02, genotypes of the $\mathrm{N}$ strain group included 238/258 bp, 240/260 bp, 240/262 bp, 242/262 bp, $244 / 262 \mathrm{bp}$ and $246 / 266 \mathrm{bp}$, while genotypes of the $\mathrm{N}_{\mathrm{F}}$ strain included 202/222 bp, 204/222 bp, 206/222 bp and 208/224 bp. For example, PRL I-MS01 exhibited a genotype consisting of 248-bp and 274-bp alleles in the $\mathrm{N}_{\mathrm{F}}$ strain and a genotype consisting of 260-bp and 288-bp alleles in N strain (Figure 3A). For PRL I-MS02, a genotype consisting of 206-bp and 222-bp alleles was observed in the $\mathrm{N}_{\mathrm{F}}$ strain, while a genotype consist of 240-bp and 260-bp alleles was observed in the $\mathrm{N}$ strain (Figure 3B). These results demonstrate that PRL I microsatellite markers can efficiently discriminate between O. niloticus strains ( $\mathrm{N}$ and $\mathrm{N}_{\mathrm{F}}$ ) based on electrophoretic genotype.

\section{Tracing the parentage of hybrid tilapia}

High proportions of commercial tilapia from Taiwan consist of hybrids of $O$. aureus and $O$. niloticus. To assess the practical ability of PRL I-MS01 and PRL I-MS02 to trace the parentage of hybrid tilapia, the genotypes of hybrid tilapia derived from mating of $\mathrm{N}$ and $\mathrm{N}_{\mathrm{F}}$ mating with A were analyzed to confirm whether the alleles at each locus matched those of the parental strains. In hybrid tilapia derived from female $\mathrm{N}$ and male A parents, the PRL I-MS01 locus exhibited 260-bp and 312-bp alleles. In hybrid tilapia derived from female $\mathrm{N}_{\mathrm{F}}$ and male A parents, the PRL-MS01 locus exhibited 248-bp and 312bp alleles. PRL I-MS02 was not able to distinguish between the A and $\mathrm{N}$ strains. Therefore, this marker can be used to trace hybrid tilapia progeny derived only from $\mathrm{N}_{\mathrm{F}}$ and $\mathrm{A}$. In the latter population, PRL

\begin{tabular}{|c|c|c|c|c|c|c|}
\hline Exp. group & Mean initial weight $(\mathbf{g})^{\mathrm{a}}$ & Mean final weight $(\mathbf{g})^{b}$ & SGR \% g/day ${ }^{c}$ & Mean initial body length [32] ${ }^{a}$ & Mean final body length [32] ${ }^{\mathrm{b}}$ & SGR $\%$ cm/dayc \\
\hline$A \times A$ & $1.29 \pm 0.35$ & $49.85 \pm 19.46$ & 2.44 & $3.02 \pm 0.38$ & $11.84 \pm 1.36$ & 0.91 \\
\hline $\mathrm{N} \times \mathrm{N}$ & $1.44 \pm 0.37$ & $165.27 \pm 34.80$ & 3.16 & $3.16 \pm 0.32$ & $17.18 \pm 1.25$ & 1.27 \\
\hline$N_{F} \times N_{F}$ & $1.47 \pm 0.26$ & $240.47 \pm 32.24$ & 3.47 & $2.98 \pm 0.34$ & $19.88 \pm 1.31$ & 1.27 \\
\hline$N \times A$ & $1.78 \pm 0.27$ & $146.67 \pm 35.73$ & 2.94 & $3.14 \pm 0.22$ & $16.55 \pm 1.30$ & 1.11 \\
\hline$N_{F} \times A$ & $1.47 \pm 0.33$ & $174.02 \pm 31.09$ & 3.18 & $2.97 \pm 0.23$ & $17.77 \pm 1.29$ & 1.19 \\
\hline
\end{tabular}

aMeasured at the beginning of the growth period (one month).

${ }^{\mathrm{b}}$ Measured at the end of the growth period (six month).

${ }^{c}$ Calculated over the growth period from one to six months.

Table 2: Comparison of specific growth rates (SGR\%) based on body length and weight difference betweenO. aureus (A), O. niloticus $(\mathrm{N})$, O.niloticus $\left(\mathrm{N}_{\mathrm{F}}\right)$ and hybrid tilapia over a six-month periods. 
Citation: Chi JR, Huang CW, Hu SY, Wu JL (2014) Prolactin I microsatellite as genetic markers for characterization of five Oreochromis tilapia species and two Oreochromis niloticus strains. J Aquac Res Development 5: 251 doi:10.4172/2155-9546.1000251

Page 5 of 7

\begin{tabular}{|c|c|c|c|c|c|c|c|}
\hline Marker & Genotypes & $\mathrm{N}$ strain & $\mathrm{N}_{\mathrm{F}}$ strain & Marker & Genotype & $\mathbf{N}$ strain & $\mathrm{N}_{\mathrm{F}}$ strain \\
\hline \multirow[t]{7}{*}{ PRL I-MS01 } & $248 / 274$ & 0.00 & 0.68 & \multirow[t]{7}{*}{ IGFII-MS01 } & $218 / 218$ & 0.00 & 0.12 \\
\hline & $250 / 276$ & 0.00 & 0.32 & & $218 / 238$ & 0.08 & 0.00 \\
\hline & $258 / 284$ & 0.12 & 0.00 & & $220 / 220$ & 0.36 & 0.24 \\
\hline & $260 / 286$ & 0.20 & 0.00 & & $220 / 238$ & 0.00 & 0.04 \\
\hline & $260 / 288$ & 0.40 & 0.00 & & $222 / 222$ & 0.56 & 0.56 \\
\hline & $264 / 288$ & 0.16 & 0.00 & & $222 / 238$ & 0.00 & 0.04 \\
\hline & $264 / 290$ & 0.12 & 0.00 & & & & \\
\hline \multirow[t]{11}{*}{ PRL I-MS02 } & $202 / 222$ & 0.00 & 0.12 & \multirow[t]{19}{*}{ IGFII-MS03 } & $192 / 234$ & 0.00 & 0.04 \\
\hline & $204 / 222$ & 0.00 & 0.16 & & $200 / 222$ & 0.00 & 0.05 \\
\hline & $206 / 222$ & 0.00 & 0.36 & & $214 / 214$ & 0.00 & 0.14 \\
\hline & $206 / 224$ & 0.00 & 0.32 & & $214 / 234$ & 0.00 & 0.19 \\
\hline & $208 / 224$ & 0.00 & 0.04 & & $216 / 216$ & 0.04 & 0.05 \\
\hline & $238 / 258$ & 0.04 & 0.00 & & $216 / 224$ & 0.12 & 0.00 \\
\hline & $240 / 260$ & 0.28 & 0.00 & & $216 / 236$ & 0.00 & 0.14 \\
\hline & $240 / 262$ & 0.08 & 0.00 & & $216 / 256$ & 0.12 & 0.05 \\
\hline & $242 / 262$ & 0.20 & 0.00 & & $220 / 220$ & 0.04 & 0.14 \\
\hline & $244 / 262$ & 0.20 & 0.00 & & $220 / 230$ & 0.28 & 0.00 \\
\hline & $246 / 266$ & 0.20 & 0.00 & & $220 / 240$ & 0.00 & 0.05 \\
\hline \multirow[t]{9}{*}{ GH-MS01 } & $158 / 158$ & 0.36 & 0.08 & & $220 / 262$ & 0.04 & 0.00 \\
\hline & $158 / 226$ & 0.00 & 0.04 & & $220 / 276$ & 0.08 & 0.00 \\
\hline & $160 / 160$ & 0.00 & 0.28 & & $222 / 230$ & 0.00 & 0.10 \\
\hline & $160 / 218$ & 0.00 & 0.16 & & $226 / 242$ & 0.00 & 0.05 \\
\hline & $160 / 222$ & 0.40 & 0.16 & & $228 / 272$ & 0.04 & 0.00 \\
\hline & $160 / 224$ & 0.24 & 0.00 & & $228 / 276$ & 0.12 & 0.00 \\
\hline & $160 / 226$ & 0.00 & 0.16 & & $230 / 274$ & 0.08 & 0.00 \\
\hline & $160 / 230$ & 0.00 & 0.04 & & $272 / 272$ & 0.04 & 0.00 \\
\hline & $164 / 164$ & 0.00 & 0.08 & & & & \\
\hline \multirow[t]{7}{*}{ ISP-MS01 } & $230 / 248$ & 0.44 & 0.00 & & & & \\
\hline & $230 / 250$ & 0.20 & 0.00 & & & & \\
\hline & $232 / 252$ & 0.08 & 0.00 & & & & \\
\hline & $234 / 254$ & 0.00 & 0.28 & & & & \\
\hline & $236 / 246$ & 0.28 & 0.24 & & & & \\
\hline & $236 / 254$ & 0.00 & 0.28 & & & & \\
\hline & $238 / 256$ & 0.00 & 0.20 & & & & \\
\hline
\end{tabular}

Table 3: Genotypic distribution of six microsatellite markers between O. niloticus $(\mathrm{N})$ and O. niloticus $\left(\mathrm{N}_{\mathrm{F}}\right)$ tilapia strains $(\mathrm{N}=25)$.

\begin{tabular}{|c|c|c|c|}
\hline Strain & Locus & Allele size & Microsatellite copy numbers \\
\hline $\mathrm{N} \times \mathrm{N}$ & PRL I-MS01 & $264 \mathrm{bp}$ & $(\mathrm{GT})_{35}$ \\
\hline $\mathrm{N}_{\mathrm{F}} \times \mathrm{N}_{\mathrm{F}}$ & PRL I-MS01 & $248 \mathrm{bp}$ & $(\mathrm{GT})_{27}$ \\
$\mathrm{~N} \times \mathrm{N}$ & PRL I-MS02 & $240 \mathrm{bp}$ & $(\mathrm{CA})_{33}$ \\
\hline $\mathrm{N}_{\mathrm{F}} \times \mathrm{N}_{\mathrm{F}}$ & PRL I-MS02 & $206 \mathrm{bp}$ & $(\mathrm{CA})_{16}$ \\
\hline
\end{tabular}

Table 4: Copy numbers of PRL I-MS01 and PRL I-MS02 microsatellites in $O$. niloticus $(\mathrm{N})$ and $\mathrm{O}$. Niloticus.

I-MS02 exhibited 206-bp and 246-bp alleles derived from the maternal $\mathrm{N}_{\mathrm{F}}$ strain and a 246-bp allele derived from the paternal A strain (Figure 3B). These results demonstrate that the PRL I-MS01 microsatellite marker can be used to trace the origin of hybrid tilapia products.

\section{Characterization of tandem repeats within PRL I microsatellite loci}

Based on sequences obtained from Gene Bank database (NCBI Accession no. X92380), GT and CA tandem repeats are known to exist in the PRL I-MS01 and PRL I-MS02 microsatellite loci. However, the copy numbers of GT and CA tandem repeats in the $\mathrm{N}$ and $\mathrm{N}_{\mathrm{F}}$ strains are unclear. Most microsatellite genotypes in the $\mathrm{N}$ strain consisted of 260-bp and 288-bp alleles (PRL I-MS01) and 240-bp and 260-bp alleles (PRL I-MS02). In the $\mathrm{N}_{\mathrm{F}}$ strain, the PRL I-MS01 and PRL I-MS02 microsatellite genotypes were $248 / 274$ bp and $206 / 222$ bp, respectively.
To clarify differences in tandem repeats between $\mathrm{N}$ and $\mathrm{N}_{\mathrm{F}}$, small alleles of PRL I-MS01 and PRL I-MS02 were cloned and sequenced to identify the copy numbers of tandem repeats. As shown in Table 4, the numbers of GT tandem repeats in $\mathrm{N}$ and $\mathrm{N}_{\mathrm{F}}$ were 35 and 27, respectively, while the numbers of CA tandem repeats in $\mathrm{N}$ and $\mathrm{N}_{\mathrm{F}}$ were 33 and 16, respectively. These results further demonstrate that PRL I-MS01 and PRL I-MS02 are useful genetic markers to characterize O. niloticus tilapia strains.

\section{Discussion}

Tilapia has become the second most important aquaculture fish in the world. Therefore, researchers worldwide have endeavored to improve its growth characteristics. From an economic benefits perspective, farm-raised tilapia selected for large body size are almost exclusively male because of the xenogenic hybridization technology used. Taiwan is one of the major tilapia-producing countries and is an important supplier to the global market. In Taiwan, five major Oreochromis tilapia species, including $O$. aureus (A), O. mossambicus (M), O. hornorum $(\mathrm{H})$, O. spilurus $(\mathrm{S})$, and O. niloticus $(\mathrm{N})$, and one O. niloticus strain $\left(\mathrm{N}_{\mathrm{F}}\right)$ with a rapid-growth phenotype have been conserved at the Freshwater Aquaculture Research Center (FARC). Most farmed hybrid tilapia is derived from crosses between $\mathrm{A}$ and $\mathrm{N}$ or $\mathrm{N}_{\mathrm{F}}$. Characterization of tilapia species using genetic analysis 
to supplement conventional approaches is required to strengthen the tilapia aquaculture industry and facilitate optimal breeding. Microsatellite markers have been used previously to identify tilapia species, trace parentage, measure genetic diversity and facilitate genetic mapping [4,21-25].

We used six microsatellite regions located within four growthrelated genes, including IGF-II, PRL-I, GH and insulin, to discriminate between five tilapia species. Only two microsatellite markers located in the promoter region of the PRL I gene could be used to identify species of tilapia. We found that the genotypes of $\mathrm{A}, \mathrm{M}, \mathrm{H}$ and $\mathrm{N}$ could be differentiated using PRL I-MS01. However, the genotypes of these four strains could not be differentiated using PRL I-MS02. The genotype of S could be uniquely distinguished from the other four species using PRL I-MS01. These results demonstrate that the combination of the PRL I-MS01 and PRL I-MS02 microsatellite markers can characterize the five tilapia species examined.

Prolactin (PRL) is a hormone released by the pituitary gland. It is similar in structure and function to growth hormone $(\mathrm{GH})$ and somatolactin (SL). In fish, PRL is involved in the regulation of electrolyte homeostasis and immune function [26,27]. Furthermore, knockdown of the PRL gene in zebrafish embryos leads to phenotypes of shorter body length and smaller head and eye size, suggesting that PRL is also involved in growth [18]. The $\mathrm{N}$ and $\mathrm{N}_{\mathrm{F}}$ strains of $O$. niloticus exhibit significant differences in body size, body weight and specific growth rate. Farmed hybrid tilapia produced by crossing A with $\mathrm{N}$ or $\mathrm{N}_{\mathrm{F}}$ also show differences in body size, body weight and specific growth rate. To assess whether the difference in growth performance between $\mathrm{N}$ and $\mathrm{N}_{\mathrm{F}}$ can be predicted by PRL I microsatellites, the genotypes of $\mathrm{N}$ and $\mathrm{N}_{\mathrm{F}}$ were analyzed using PRL I-MS01 and PRL I-MS02. Our findings reveal that both microsatellite regions are efficient genetic markers to distinguish between $\mathrm{N}$ and $\mathrm{N}_{\mathrm{F}}$ tilapia strains. Traceability of farmed hybrid tilapia is important to ensure the overall quality and safety of farm-raised tilapia. PRL I microsatellites were also used to verify whether the genotypes of hybrid tilapia match those of their parents. Our findings reveal that the progeny of hybrid tilapia inherit PRL I alleles from the paternal and maternal genotypes at this locus. Thus, the origin of hybrid tilapia can be traced based on PRL I microsatellite genotypes.

Recent studies have demonstrated that functional microsatellites located in protein-coding regions, untranslated regions (UTRs) and introns can regulate gene expression and function by affecting transcription and translation $[10,11,28]$. For example, the microsatellite in the 5' flanking region of the GH gene of teleosts is associated with growth [29]. Furthermore, CA tandem repeats within intron 1 of the IGF-I gene affect circulating concentrations of IGF-I in swine [30]. Sequence data confirms that the copy numbers of GT tandem repeats in PRL I-MS01 and CA tandem repeats in PRL I-MS02 vary significantly between the $\mathrm{N}$ and $\mathrm{N}_{\mathrm{F}}$ tilapia strains. Streelman and Kocher [24] have demonstrated that different lengths of PRL I microsatellite alleles with CA repeats can affect gene expression $[31,32]$. The difference in copy number of PRL I microsatellites may affect the diversity of PRL I gene expression, further influencing the observed growth performance differences between $\mathrm{N}$ and $\mathrm{N}_{\mathrm{F}}$. This hypothesis requires further study.

Nevertheless, it is not clear whether selection for low cortisol response is always recommendable. Further analysis will be carried out on the consistency of stress/cortisol response on this and the next generation to see whether the selection for this characteristic may help to decrease husbandry problems and improve the profitability of aqua cultured fish.
We found that PRL I microsatellites, including PRL I-MS01 and PRL I-MS02, are useful genetic markers to characterize Oreochromis tilapia species and to distinguish between the $\mathrm{N}$ and $\mathrm{N}_{\mathrm{F}}$ strains of O. niloticus. Microsatellite markers will provide an efficient tool to strengthen the management of the tilapia aquaculture industry and facilitate the conventional breeding of superior strains.

\section{Acknowledgment}

We thank Dr. Fu-Guang Liu at Freshwater Aquaculture Research Center Fisheries Research Institute, Taiwan for providing tilapia species and our laboratory colleagues for their constructive criticism and suggestions. This research was supported by grants from the Council of Agriculture (96AS-1.1.2.-FA-F1) and the National Science Council (NSC 94- 2317-B-001).

\section{References}

1. Maldini M, Nonnis Marzano F, Fortes GG, Papa R, Gandolfi G (2006) Fish and seafood traceability based on AFLP markers: Elaboration of a species database. Aquaculture 261: 487-494.

2. Jérôme $M$, Martinsohn JT, Ortega $D$, Carreau P, Vérrez-Bagnis V, et al. (2008) Toward fish and seafood traceability: anchovy species determination in fish products by molecular markers and support through a public domain database. J Agric Food Chem 56: 3460-3469.

3. Rognon X and Guyomard R (1997) Mitochondrial DNA differentiation among East and West African Nile tilapia populations. J Fish Biol 51: 204-207.

4. Ezaz MT, Harvey SC, Boonphakdee C, Teale AJ, McAndrew BJ, et al. (2004) Isolation and physical mapping of sex-linked AFLP markers in nile tilapia (Oreochromis niloticus L.). Mar Biotechnol (NY) 6: 435-445.

5. Bardakci F and Skibinski DO (1999) A polymorphic SCAR-RAPD marker between species of tilapia (Pisces: Cichlidae). Anim Genet 30: 78-79.

6. Bardakci F and Skibinski DO (1994) Application of the RAPD technique in tilapia fish: species and subspecies identification. Heredity 73: 117-123

7. Naish KA, Warren M, Bardakci F, Skibinski DO, Carvalho GR, et al. (1995) Multilocus DNA fingerprinting and RAPD reveal similar genetic relationships between strains of Oreochromis niloticus (Pisces: Cichlidae). Mol Ecol 4: 271 274

8. Seyoum S, Kornfield I (1992) Identification of the subspecies of Oreochromis niloticus (Pisces: Cichlidae) using restriction endonuclease analysis of mitochondrial DNA. Aquaculture 102: 29-42.

9. Liu ZJ and Cordes JF (2004) DNA marker technologies and their applications in aquaculture genetics. Aquaculture 238: 1-37.

10. Chistiakov DA, Hellemans B, Volckaert FAM (2006) Microsatellites and their genomic distribution, evolution, function and applications: A review with special reference to fish genetics. Aquaculture 255: 1-29.

11. Li YC, Korol AB, Fahima T, Nevo E (2004) Microsatellites within genes: structure, function, and evolution. Mol Biol Evol 21: 991-1007.

12. Liu Z, Li P, Kocabas A, Karsi A, Ju Z (2001) Microsatellite-containing genes from the channel catfish brain: evidence of trinucleotide repeat expansion in the coding region of nucleotide excision repair gene RAD23B. Biochem Biophys Res Commun 289: 317-324.

13. Sharopova N (2008) Plant simple sequence repeats: distribution, variation, and effects on gene expression. Genome 51: 79-90.

14. Kashi $Y$ and King DG (2006) Simple sequence repeats as advantageous mutators in evolution. Trends in Genetics 22: 253-259.

15. Pérez-Sánchez J and Le Bail PY (1999) Growth hormone axis as marker of nutritional status and growth performance in fish. Aquaculture 177: 117-128.

16. Chen JY, Chen JC, Chang CY, Shen SC, Chen MS, et al. (2000) Expression of recombinant tilapia insulin-like growth factor-I and stimulation of juvenile tilapia growth by injection of recombinant IGFs polypeptides. Aquaculture 181: 347-360.

17. Castillo J, Codina M, Martinez ML, Navarro I, Gutierrez J (2004) Metabolic and mitogenic effects of IGF-I and insulin on muscle cells of rainbow trout. Am J Physiol Regul Integr Comp Physiol 286: R935-941.

18. Zhu Y, Song D, Tran N-T, Nguyen N (2007) The effects of the members of growth hormone family knockdown in zebrafish development. General and Comparative Endocrinology 150: 395-404. 
Citation: Chi JR, Huang CW, Hu SY, Wu JL (2014) Prolactin I microsatellite as genetic markers for characterization of five Oreochromis tilapia species and two Oreochromis niloticus strains. J Aquac Res Development 5: 251 doi:10.4172/2155-9546.1000251

19. Yue GH and Orban L (2002) Microsatellites from genes show polymorphism in two related Oreochromis species. Molecular Ecology Notes 2: 99-100.

20. Fessehaye Y, El-bialy Z, Rezk MA, Crooijmans R, Bovenhuis H, et al. (2006) Mating systems and male reproductive success in Nile tilapia (Oreochromis niloticus) in breeding hapas: A microsatellite analysis. Aquaculture 256: 148 158

21. Romana-Eguia MRR, Ikeda M, Basiao ZU, Taniguchi N (2004) Genetic diversity in farmed Asian Nile and red hybrid tilapia stocks evaluated from microsatellite and mitochondrial DNA analysis. Aquaculture 236: 131-150.

22. Cnaani A, Kocher TD (2008) Sex-linked markers and microsatellite locus duplication in the cichlid species Oreochromis tanganicae. Biol Lett 4: 700-703.

23. Cnaani A, Zilberman N, Tinman S, Hulata G, Ron M (2004) Genome-scan analysis for quantitative trait loci in an F 2 tilapia hybrid. Molecular Genetics and Genomics 272: 162-172.

24. Kocher TD, Lee WJ, Sobolewska H, Penman D, McAndrew B (1998) A Genetic Linkage Map of a Cichlid Fish, the Tilapia (Oreochromis niloticus). Genetics 148: 1225-1232.

25. Lee BY, Lee WJ, Streelman JT, Carleton KL, Howe AE, et al. (2005) A secondgeneration genetic linkage map of tilapia (Oreochromis spp.). Genetics 170: 237-244.

26. Poncelet AC, Levavi-Sivan B, Muller M, Yaron Z, Martial J, et al. (1996) The
Tilapia Prolactin I Gene: Evolutionary Conservation of the Regulatory Elements Directing Pituitary-Specific Expression. DNA and Cell Biology 15: 679-692.

27. Yada T, Uchida K, Kajimura S, Azuma T, Hirano T, et al. (2002) Immunomodulatory effects of prolactin and growth hormone in the tilapia, Oreochromis mossambicus. J Endocrinol 173: 483-492.

28. Sharma VK, Kumar N, Brahmachari SK, Ramachandran S (2007) Abundance of dinucleotide repeats and gene expression are inversely correlated: a role for gene function in addition to intron length. Physiol Genomics 31: 96-103.

29. Almuly R, Poleg-Danin Y, Gorshkov S, Gorshkova G, Rapoport B, et al. (2005) Characterization of the $5^{\prime}$ flanking region of the growth hormone gene of the marine teleost, gilthead sea bream Sparus aurata: analysis of a polymorphic microsatellite in the proximal promoter. Fisheries Science 71: 479-490.

30. Estany J, Tor M, Villalba D, Bosch L, Gallardo D, et al. (2007) Association of CA repeat polymorphism at intron 1 of insulin-like growth factor (IGF-I) gene with circulating IGF-I concentration, growth, and fatness in swine. Physiol Genomics 31: $236-243$

31. Streelman JT and Kocher TD (2002) Microsatellite variation associated with prolactin expression and growth of salt-challenged tilapia. Physiol Genomics 9: $1-4$

32. Tomas FM, Pym RA, McMurtry JP, Francis GL (1998) Insulin-like growth factor (IGF)-I but not IGF-II promotes lean growth and feed efficiency in broiler chickens. Gen Comp Endocrinol 110: 262-275. 